\title{
Correlates Associated with Unipolar Depressive Disorders in a Latino Population
}

\author{
Virmarie Correa-Fernández ${ }^{\mathrm{a}}$ José R. Carrión-Baralt ${ }^{\mathrm{b}}$ Margarita Alegría ${ }^{\mathrm{c}}$ \\ Carmen E. Albizu-García ${ }^{a}$ \\ aDepartment of Health Disparities Research, The University of Texas MD Anderson Cancer Center, Houston, Tex., \\ ${ }^{b}$ Department of Human Development, Graduate School of Public Health, Medical Science Campus, University \\ of Puerto Rico, San Juan, P.R., and ' Center for Multicultural Mental Health Research, Harvard Medical School, \\ Somerville, Mass., USA
}

\section{Key Words}

Dysthymia • Major depression • Double depression • Continuity controversy

\begin{abstract}
Background: This study reports the comparison and associations of demographic, clinical and psychosocial correlates with three unipolar depressive disorders: dysthymia (DYS), major depression (MD) and double depression (DD), and examines to which extent these variables predict the disorders. Sampling and Method: Previously collected data from 563 adults from a community in Puerto Rico were analyzed. One hundred and thirty individuals with DYS, 260 with MD and 173 with DD were compared by demographic variables, psychiatric and physical comorbidity, familial psychopathology, psychosocial stressors, functional impairment, self-reliance, problem recognition and formal use of mental health services. Multinomial regression was used to assess the association of the predictor variables with each of the three disorders. Results: Similarities outweighed the discrepancies between the disorders. The main differences observed were between MD and DD, while DYS shared common characteristics with both $\mathrm{MD}$ and $\mathrm{DD}$. After other variables were controlled, anxiety, functional impairment and problem recog-
\end{abstract}

nition most strongly predicted a DD diagnosis, while age predicted a DYS diagnosis. Conclusion: MD, DYS and DD are not completely different disorders, but they do differ in key aspects that might be relevant for nosology, research and practice. A dimensional system that incorporates specific categories of disorders would better reflect the different manifestations of unipolar depressive disorders.

Copyright $\odot 2012$ S. Karger AG, Basel

\section{Introduction}

A fundamental issue regarding the validity of current psychiatric nomenclature is the differentiation among diagnostic categories and whether mental disorders are in fact different conditions or stages of a disease spectrum $[1,2]$. This so-called 'continuity controversy' attempts to elucidate whether mental disorders are different from each other and that a case is qualitatively different from a person with few or no symptoms (categorical perspective), or if there is a spectrum or gradient along which symptoms and phenomenology can be situated as a function of their severity (dimensional perspective) [3]. A variety of methods have been used to address this controversy. These include taxometric statistical methods, com-

\section{KARGER}

Fax +41613061234

E-Mail karger@karger.ch

www.karger.com (c) 2012 S. Karger AG, Basel

0254-4962/13/0463-0163\$38.00/0

Accessible online at:

www.karger.com/psp
Virmarie Correa-Fernández, $\mathrm{PhD}$

The University of Texas MD Anderson Cancer Center

Department of Health Disparities Research, 1400 Herman Pressler, Unit 1440

Houston, TX 77230-1402 (USA)

E-Mail vcorrea@mdanderson.org 
parison of impairment indexes, psychiatric and physical comorbidity, biological aspects, and familial aggregation of psychopathology [4-9]. Other studies are based theoretically on models of nosological validity $[10,11]$.

The continuity controversy extends to mood disorders, which have a high morbidity and lifetime prevalence of between 1.5 and $19 \%$ as reported in studies all over the world $[12,13]$. Although within current psychiatric and psychological practice unipolar depressive disorders are treated as discrete conditions, research suggests that clinical depression and subthreshold syndromes differ mainly in intensity or duration $[6,7]$ and that mild chronic depression shares several clinical, biological and pharmacological characteristics with major depression, suggesting that they are different expressions of severity of the same parent disease [14-16]. Other authors still argue in favor of the categorical perspective [9] because it facilitates communication between professionals and influences clinical decisions.

Angst et al. [17] provided an important contribution to the field by investigating the classification of depression in a prospective community-based cohort study. These authors proposed a hierarchical spectrum of depression whereby people without any diagnosis of depression were at one end of the spectrum and those with bipolar disorders were at the other end. Between these two end points they placed, in ascending order of severity, subthreshold cases, those with only one subtype, and those with combined depressive disorders. Along these lines, there is a growing literature focusing on the differences and similarities between various depressive disorders, and those that have been undertaken have been inconsistent in the way clinical and psychosocial variables are associated with the existing diagnostic categories of depression [18-20]. Thus, further understanding of the factors that differentiate specific categories such as major depression (MD), dysthymia (DYS) and the so-called double depression (DD) [21] is urgently needed to inform the current debate regarding the continuity controversy of unipolar depressive disorders and potentially the development of the fifth edition of the Diagnostic and Statistical Manual of Mental Disorders [22, 23].

Some limitations of previous studies arise from the inclusion of subjects with different depressive syndromes in the same diagnostic group, and the small number of cases with pure DYS $[3,8]$. Both of these aspects may obscure the real differences between diagnostic categories. In addition, whereas important research related to the classification of depressive psychopathology has focused on clinical populations [20,24-26], community-based stud- ies are required because a large proportion of individuals with depressive conditions do not seek care for their mental health problems in the clinical setting [27]. In addition, even though the goal of current classification systems has been to provide definitions of mental disorders that are applicable across ethnicities and contexts [10], to the best knowledge of the authors, the similarities and differences among current categories of unipolar depression have been rarely explored with a Latino population [28]. This study aims to contribute to filling this gap by addressing these limitations in knowledge.

The present study is grounded in the conceptual model for the classification of psychopathology as proposed by Cantwell [10]. This conceptual model, elaborated from the classic work of Robins and Guze [11], argued that for diagnostic categories to be valid they should differ in some aspects besides clinical phenomenology (psychosocial factors, demographic factors, biological factors, genetic factors, natural history of the disorder and response to therapeutic intervention). Thus, Cantwell's model provides an appropriate framework for this investigation, whose main objective was to explore similarities and differences in sociodemographic, clinical and psychosocial correlates among adult Puerto Ricans with MD, DYS and DD.

\section{Methods}

The present investigation undertook secondary data analysis from the longitudinal study Mental Health Care Utilization among Puerto Ricans (National Institute of Mental Health grant), conducted with a probabilistic and representative community sample of adult Puerto Ricans. The survey area contained $57 \%$ of the total population living in poverty on the island. Lay interviewers collected the data through face-to-face interviews. In-depth details of the study design and subject selection criteria have been published previously [29, 30].

Only persons who fulfilled the criteria for MD, DYS or DD were selected for this investigation. Participants were selected from any of the three waves of the original study and pooled for the current set of analyses. Nevertheless, there is a single observation for each participant and all correlates were measured for the year preceding the interview. For a person to be considered positive for DYS or MD, he or she had to meet the diagnostic criteria for the respective category during the preceding year or previous 6 months, but could not have met the diagnostic criteria for the other depressive category at the time of the interview or in the past. For a person to be considered positive for DD, he or she had to meet the criteria for an MD episode as well as for DYS in the preceding year. It is important to note that individuals with a history of any of the conditions but who did not meet the full diagnostic criteria during the preceding year were excluded from the sample. Finally, the sample was comprised of 563 participants. 
Specifically, 130 respondents fulfilled the criteria for DYS, 260 for $\mathrm{MD}$ and 173 for DD.

\section{Diagnostic Definitions}

The dependent variable in this study is the depressive disorder, which assumes three possible levels: DYS, MD and DD. The diagnoses of these conditions were derived using the depression module of the Spanish version of the Composite International Diagnostic Interview [31], which is a structured, lay-administered psychiatric interview. These definitions are still applicable because the core diagnostic criteria for DYS and MD did not change in the DSM-IV (text revision) [22].

\section{Predictor Variables}

Demographic Characteristics. Age and education were assessed in years. Urbanicity, gender, marital status and employment status were treated as categorical variables.

Clinical Variables. Certain psychiatric disorders were assessed for in the original study because of their known comorbidity with depressive disorders [13]. Anxiety was measured using a subscale of the Psychiatric Symptoms and Dysfunction Scale. Somatization was diagnosed using the Diagnostic Interview Schedule, a structured interview widely used in population-based studies [13]. Alcohol abuse or dependence was measured by the alcohol module of the Composite International Diagnostic Interview. All three scales are adequate measures of mental health problems among Hispanics in the United States as well as among Puerto Ricans [31-33]. Physical illness is an aggregate measure ranging in value between 0 and 60 that was constructed based on the number of physical conditions reported by the participant and the associated level of impairment ( $1=$ not interfering with daily activities, $5=$ interfering a lot). The final value was calculated by adding the corresponding level of impairment of each of the conditions reported. The functional impairment index ranges from 0 to 8 and includes aspects of impairment and severity associated with a mental health problem. A cutoff point of 2 is associated with impairment [34]. Formal use of mental health services measured whether the participant reported visiting a professional to discuss a mental health, drug or alcohol problem.

Psychosocial Variables. Psychosocial variables have also been associated with depressive disorders [34]. Participants were asked eight yes-or-no questions about drug and alcohol abuse, suicide attempt, and impairment and treatment for mental health problems in first-degree relatives. This information served to define familial psychopathology as a continuous measure. Social support was measured by noting the mean number of relatives or friends with whom the respondents felt comfortable or from whom they could seek advice. Economic strain explored whether the participant thought there was enough money to satisfy basic needs. Recognition of a mental health problem was measured by means of two questions that explored whether a respondent, a family member or a friend perceived that the respondent had a mental or emotional problem [31]. Self-reliance was measured with a single question of whether the person preferred to solve emotional problems by himself or herself [35]. All the correlates were measured for the year preceding the interview.

Data Analyses

Descriptive statistics were used to show the frequency of all independent variables by diagnosis. The $\chi^{2}$ test was used to exam- ine the association between categorical independent variables and the diagnostic groups. Differences between group means for continuous independent variables were analyzed by analysis of variance tests, and pairwise comparisons were conducted using the Bonferroni or Games-Howell post hoc tests. Finally, a hierarchical multivariate multinomial logistic regression analysis was used to estimate the contribution of each independent variable to the probability of meeting the criteria for MD, DYS or DD when the other predictor variables were controlled [36]. The hierarchy was structured as follows: (1) demographic characteristics, (2) clinical variables and (3) psychosocial variables. Demographic variables were entered first as they are typical control variables. We then entered the clinical variables as theory, previous research and our own simple multinomial analyses (data not shown in this publication) revealed that the majority of variables distinguishing these disorders are among the clinical predictors. Finally, we entered other psychosocial variables which could potentially contribute to strengthening an already significant model. In each step, nonsignificant terms were removed from the model one by one before adding variables of the next step. Predictor variables in steps 2 and 3 were added, respectively, to those that were significant in the previous step $(\mathrm{p}<0.05)$. In order to facilitate the interpretation of results, the categorical form of functional impairment was used, and economic strain was transformed into a dummy variable (0 = low, 1 = high).

The multinomial regression analysis (also known as polytomous regression) is used when the question under study is to explore the relationship of one or more risk factors or variables to a disease outcome that has three or more categories [36]. One of the categories of the outcome variables is designated as the reference category and each of the other levels is compared with this reference. The choice of the reference category does not affect the results.

In this study, MD was selected as the reference category because it was the only episodic condition. Hence, the analysis provides two separate odds ratios (ORs) for DD versus MD and for DYS versus MD. The comparisons between DD and DYS are inferred from the two expressions drawn from the model because the sum of probabilities for the three outcomes (MD, DD or DYS) must equal 1, the total probability [36]. This type of analysis has been previously employed in similar research [28].

\section{Results}

Table 1 presents the distribution of the sample across all demographic, clinical and psychosocial variables by diagnosis.

Demographic Characteristics. The only two demographic variables that were significantly different between the diagnostic groups were age $(\mathrm{F}=9.55$, d.f. $=2$, $\mathrm{p}<0.001)$ and education $(\mathrm{F}=5.10$, d.f. $=2, \mathrm{p}<0.01)$. For both variables, the differences existed between DYS and MD and between DYS and DD. Individuals with DYS were significantly older and had less education than those with either MD or DD. 
Table 1. Comparison of sociodemographic, clinical and psychosocial variables by depressive condition

\begin{tabular}{|c|c|c|c|c|c|c|}
\hline Variable & & $\begin{array}{l}\text { DYS } \\
(n=130)\end{array}$ & $\begin{array}{l}M D \\
(n=260)\end{array}$ & $\begin{array}{l}\mathrm{DD} \\
(\mathrm{n}=173)\end{array}$ & $\begin{array}{l}\text { Total } \\
(\mathrm{n}=563)\end{array}$ & $\mathrm{p}$ \\
\hline Urbanicity & $\begin{array}{l}\text { Urban } \\
\text { Rural }\end{array}$ & $\begin{array}{l}72(55.4) \\
58(44.6)\end{array}$ & $\begin{array}{l}155(59.6) \\
105(40.4)\end{array}$ & $\begin{array}{r}105(60.7) \\
68(39.3)\end{array}$ & $\begin{array}{l}332(59.0) \\
231(41.0)\end{array}$ & 0.623 \\
\hline Gender & $\begin{array}{l}\text { Female } \\
\text { Male }\end{array}$ & $\begin{array}{l}89(68.5) \\
41(31.5)\end{array}$ & $\begin{array}{r}184(70.8) \\
76(29.2)\end{array}$ & $\begin{array}{r}124(71.7) \\
49(28.3)\end{array}$ & $\begin{array}{l}397(70.5) \\
166(29.5)\end{array}$ & 0.825 \\
\hline Marital status & $\begin{array}{l}\text { Single } \\
\text { Married } \\
\text { Disrupted }\end{array}$ & $\begin{array}{l}19(14.6) \\
71(54.6) \\
40(30.8)\end{array}$ & $\begin{array}{r}44(16.9) \\
137(52.7) \\
79(30.4)\end{array}$ & $\begin{array}{l}31(17.9) \\
79(45.7) \\
63(36.4)\end{array}$ & $\begin{array}{r}94(16.7) \\
287(51.0) \\
182(32.3)\end{array}$ & 0.518 \\
\hline Employment status & $\begin{array}{l}\text { Employed } \\
\text { Unemployed } \\
\text { Out of labor }\end{array}$ & $\begin{array}{l}37(28.5) \\
20(15.4) \\
73(56.2)\end{array}$ & $\begin{array}{r}91(35.0) \\
44(16.9) \\
125(48.1)\end{array}$ & $\begin{array}{l}47(27.2) \\
35(20.2) \\
91(52.6)\end{array}$ & $\begin{array}{r}175(31.1) \\
99(17.6) \\
289(51.3)\end{array}$ & 0.318 \\
\hline Anxiety & $\begin{array}{l}\text { Yes } \\
\text { No }\end{array}$ & $\begin{array}{l}65(50.0) \\
65(50.0)\end{array}$ & $\begin{array}{l}145(55.8) \\
115(44.2)\end{array}$ & $\begin{array}{r}128(74.0)^{\mathrm{a}, \mathrm{b}} \\
45(26.0)\end{array}$ & $\begin{array}{l}338(60.0) \\
225(40.0)\end{array}$ & $\leq 0.001$ \\
\hline Formal use of MHS & $\begin{array}{l}\text { Yes } \\
\text { No }\end{array}$ & $\begin{array}{l}44(33.8)^{\mathrm{b}} \\
86(66.2)\end{array}$ & $\begin{array}{l}101(38.8) \\
159(61.2)\end{array}$ & $\begin{array}{l}93(53.8)^{\mathrm{b}} \\
80(46.2)\end{array}$ & $\begin{array}{l}238(48.3) \\
325(57.7)\end{array}$ & $\leq 0.01$ \\
\hline Problem recognition & $\begin{array}{l}\text { Yes } \\
\text { No }\end{array}$ & $\begin{array}{l}88(67.7) \\
42(32.3)\end{array}$ & $\begin{array}{c}206(79.2)^{\mathrm{a}} \\
54(20.8)\end{array}$ & $\begin{array}{c}156(90.7)^{\mathrm{a}} \\
16(9.3)\end{array}$ & $\begin{array}{l}450(80.1) \\
112(19.9)\end{array}$ & $<0.001$ \\
\hline Self-reliance & $\begin{array}{l}\text { Yes } \\
\text { No }\end{array}$ & $\begin{array}{l}70(55.1)^{\mathrm{b}} \\
57(44.9)\end{array}$ & $\begin{array}{l}156(60.7) \\
101(39.3)\end{array}$ & $\begin{array}{l}80(46.8)^{\mathrm{a}, \mathrm{b}} \\
91(53.2)\end{array}$ & $\begin{array}{l}306(55.1) \\
249(44.9)\end{array}$ & $\leq 0.05$ \\
\hline Age, years & & $47.45 \pm 12.58$ & $41.47 \pm 13.19^{\mathrm{a}}$ & $43.51 \pm 12.15^{\mathrm{a}}$ & $43.44 \pm 12.93$ & $<0.001$ \\
\hline Education, years & & $8.40 \pm 4.38$ & $9.83 \pm 4.16^{\mathrm{a}}$ & $9.61 \pm 4.29^{\mathrm{a}}$ & $9.43 \pm 4.28$ & $\leq 0.01$ \\
\hline Physical illness & & $6.32 \pm 6.14$ & $5.93 \pm 6.63$ & $8.66 \pm 8.71^{b}$ & $6.86 \pm 7.32$ & $<0.001$ \\
\hline Functional impairment & & $2.21 \pm 1.71^{\mathrm{b}}$ & $2.81 \pm 1.88^{\mathrm{a}}$ & $3.68 \pm 1.69^{\mathrm{a}, \mathrm{b}}$ & $2.94 \pm 1.86$ & $<0.001$ \\
\hline Familial psychopathology & & $1.21 \pm 1.65$ & $1.55 \pm 2.10$ & $1.73 \pm 1.93$ & $1.52 \pm 1.95$ & 0.093 \\
\hline Social support & & $3.02 \pm 3.06$ & $2.97 \pm 3.50$ & $3.01 \pm 4.95$ & $2.99 \pm 3.90$ & 0.991 \\
\hline
\end{tabular}

Two-tailed analyses. Sample sizes vary due to missing data. Figures in parentheses are percentages. MHS $=$ Mental health services.

a Significantly different from DYS. ${ }^{\mathrm{b}}$ Significantly different from MD.

Clinical Correlates. Significant results were observed for anxiety $\left(\chi^{2}=21.47\right.$, d.f. $\left.=2, p<0.001\right)$, somatization $\left(\chi^{2}=13.23\right.$, d.f. $\left.=2, p<0.001\right)$, formal use of mental health services $\left(\chi^{2}=14.38\right.$, d.f. $\left.=2, \mathrm{p}<0.01\right)$, physical illness $(\mathrm{F}=7.89$, d.f. $=2, \mathrm{p}<0.001)$ and functional impairment $(\mathrm{F}=26.35$, d.f. $=2, \mathrm{p}<0.001)$. Individuals with $\mathrm{DD}$ reported significantly more comorbid anxiety and somatization and higher scores in physical illness than individuals in the other two diagnostic groups. Compared with individuals with $\mathrm{MD}$, the use of formal health services for a mental health problem was significantly greater among individuals with DD and significantly lower for those with DYS. The three groups differ significantly with respect to functional impairment $(\mathrm{F}=26.35$, d.f. $=2, \mathrm{p}<$ $0.001)$. Individuals with DD showed the highest degree of dysfunction, followed by those with MD and finally those with DYS.

Psychosocial Correlates. Two psychosocial variables were significantly associated with the depressive disorder variable: problem recognition $\left(\chi^{2}=24.77\right.$, d.f. $=2, \mathrm{p}<$ $0.001)$ and self-reliance $\left(\chi^{2}=8.04\right.$, d.f. $\left.=2, p<0.05\right)$. Significantly fewer individuals with DYS than with either MD or DD reported that they recognized having mental health problems. In addition, compared with respondents with DYS, those with DD lacked self-reliance whereas those with MD were more likely to prefer to resolve their emotional problems by themselves. Finally, respondents from the three diagnostic groups showed similar rates of familial psychopathology, low social support and high economic strain. 
Table 2. OR and 95\% CI for multivariate multinomial logistic regression of DD, DYS and MD on sociodemographic, clinical and psychosocial variables

\begin{tabular}{|c|c|c|c|c|}
\hline \multirow[t]{2}{*}{ Variable } & \multicolumn{2}{|c|}{ DD vs. MD } & \multicolumn{2}{|c|}{ DYS vs. MD } \\
\hline & OR & $95 \% \mathrm{CI}$ & OR & $95 \% \mathrm{CI}$ \\
\hline \multicolumn{5}{|l|}{ Step 1} \\
\hline Urbanicity, rural & 0.97 & $0.65-1.45$ & 1.10 & $0.71-1.71$ \\
\hline Gender, male & 1.04 & $0.67-1.62$ & 1.14 & $0.70-1.84$ \\
\hline $\operatorname{Age}^{\mathrm{a}}$ & 1.01 & $1.00-1.03$ & 1.03 & $1.01-1.06^{* *}$ \\
\hline Education $^{\mathrm{a}}$ & 1.01 & $0.96-1.07$ & 0.97 & $0.91-1.02$ \\
\hline \multicolumn{5}{|l|}{ Marital status } \\
\hline Single & 0.98 & $0.55-1.75$ & 1.07 & $0.54-2.12$ \\
\hline Married & 0.76 & $0.49-1.18$ & 1.048 & $0.64-1.72$ \\
\hline \multicolumn{5}{|l|}{ Employment } \\
\hline Employed & 0.76 & $0.47-1.25$ & 1.03 & $0.60-1.76$ \\
\hline Unemployed & 1.23 & $0.70-2.15$ & 1.20 & $0.62-2.31$ \\
\hline \multicolumn{5}{|l|}{ Step 2} \\
\hline Age & 1.00 & $0.98-1.02$ & 1.04 & $1.02-1.07^{* * *}$ \\
\hline Anxiety & 1.71 & $1.08-2.71^{*}$ & 0.84 & $0.51-1.41$ \\
\hline Somatization & 1.38 & $0.86-2.20$ & 1.12 & $0.65-1.94$ \\
\hline Alcohol abuse/dependence & 1.29 & $0.66-2.54$ & 2.01 & $0.97-4.18$ \\
\hline Physical illness ${ }^{\mathrm{a}}$ & 1.02 & $0.99-1.05$ & 0.98 & $0.94-1.02$ \\
\hline Functional impairment & 1.87 & $1.07-3.28^{*}$ & 0.74 & $0.44-1.23$ \\
\hline Formal use of MHS & 1.26 & $0.83-1.92$ & 0.81 & $0.50-1.31$ \\
\hline \multicolumn{5}{|l|}{ Step 3} \\
\hline Age $^{\mathrm{a}}$ & 1.01 & $0.99-1.03$ & 1.04 & $1.01-1.06^{* * *}$ \\
\hline Anxiety & 1.84 & $1.14-2.98^{* *}$ & 0.78 & $0.46-1.33$ \\
\hline Functional impairment & 2.62 & $1.36-5.05^{* *}$ & 0.82 & $0.47-1.44$ \\
\hline Familial psychopathology ${ }^{a}$ & 1.02 & $0.92-1.15$ & 0.94 & $0.82-1.07$ \\
\hline Social support ${ }^{\mathrm{a}}$ & 1.00 & $0.95-1.05$ & 0.10 & $0.94-1.06$ \\
\hline Problem recognition & 1.51 & $0.75-3.09$ & 0.73 & $0.41-1.30$ \\
\hline Self-reliance & 0.68 & $0.43-1.07$ & 0.93 & $0.57-1.50$ \\
\hline Economic strain & 1.05 & $0.66-1.68$ & 1.26 & $0.77-2.06$ \\
\hline \multicolumn{5}{|l|}{ Final Model } \\
\hline Age & 1.01 & $0.99-1.02$ & 1.04 & $1.02-1.05^{* * *}$ \\
\hline Anxiety & 1.99 & $1.30-3.05^{* *}$ & 0.81 & $0.50-1.31$ \\
\hline Functional impairment & 2.03 & $1.14-3.06^{*}$ & 0.86 & $0.51-1.44$ \\
\hline Problem recognition & 1.58 & $0.82-3.02$ & 0.65 & $0.38-1.12$ \\
\hline
\end{tabular}

Comparison groups: step 1 - urban, female, dissolved relationship, and out of the labor force; step 2 - absence of anxiety, absence of somatization, absence of alcohol abuse/dependence, absence of functional impairment, and no formal use of MHS; step 3 - absence of anxiety, absence of functional impairment, lack of problem recognition, lack of self-reliance, and low economic strain. MHS = Mental health services. ${ }^{* *} \mathrm{p} \leq 0.001 ;{ }^{* *} \mathrm{p} \leq$ $0.01 ;{ }^{*} \mathrm{p} \leq 0.05$; two-tailed.

${ }^{a}$ Continuous variable.

\section{Multivariate Multinomial Regression Analyses}

Table 2 shows the results of the multivariate multinomial regression analyses by presenting two different equations: DD versus MD and DYS versus MD. It is important to note that, before interpreting the individual predictors, the model itself (model fitting information for the set of variables) was statistically significant at each step $(\mathrm{p}<0.05)$. Specifically, step 1 (demographic predictors) revealed that, when other demographic variables were controlled, only age remained significant. Older 
persons were more likely to meet the criteria for DYS than for $\mathrm{MD}(\mathrm{OR}=1.03$ increase per year). In step 2 (clinical predictors plus age), when other clinical variables were controlled, anxiety and functional impairment (OR = 1.71 and 1.87, respectively, per degree of impairment) remained significantly associated with DD compared with MD. Age continued to predict DYS in this step. Step 3 (psychosocial predictors plus age, anxiety and functional impairment) revealed that no psychosocial variables were statistically significant after other predictors in this step were included in the model. However, age, anxiety and functional impairment remained significant at this step. In addition, as the psychosocial variables were eliminated from the model one by one, problem recognition acquired significance $(p<0.05)$ and was, therefore, included in the final model. For instance, problem recognition significantly predicted DD in comparison with DYS $(\mathrm{p}<0.05$; data from regression equation not shown). In sum, after several demographic, clinical and psychosocial variables are taken into account, only anxiety, functional impairment and problem recognition predicted a DD diagnosis while age predicted a DYS diagnosis. The Nagelkerke's $\mathrm{R}^{2}$ goodness-of-fit index for this final model is 0.142 .

\section{Discussion}

The multiple editions of the Diagnostic and Statistical Manual of Mental Disorders and the International Classification of Diseases are evidence of the gradual changes in psychiatric thinking regarding the nosology of mental disorders. Despite the evolution in the categorization of disorders, current diagnoses continue to be redefined because they do not completely reflect the different manifestations observed in clinical practice. Based on the theoretical model proposed by Cantwell [10] for the classification of psychopathology, a comparison of demographic, clinical and psychosocial correlates of psychiatric conditions contributes to the understanding of the differences and similarities among them and potentially sheds light on their nosology. We focused specifically on gathering evidence useful for assessing which demographic, clinical and psychosocial variables were predictive of DYS, MD and DD in a Latino population.

In the present study, which used adults sampled from a community in Puerto Rico, a lack of variability was found between DYS, MD and DD and the following variables: urbanicity, gender, marital status, employment status, alcohol abuse/dependence, familial psychopathology, social support and economic strain. Consistent with the literature of depressive disorders [13,37], the subjects in this sample reported low social support and high economic strain, but these variables did not seem to differentiate the depressive conditions. Because the study sample was composed of mainly low-socioeconomic individuals, economic strain was a better indicator than income of the relationship between the economic level and the different depressive conditions [29].

Although individuals with DYS, MD and DD had many similarities, they also differed in some of the variables under study. The dysthymic respondents differed from those with MD in age, education, functional impairment, self-reliance, recognition of a mental health problem and formal use of services only when these factors interacted with each other. However, when other factors were controlled, only age predicted a DYS diagnosis, in that individuals who met the criteria for MD were significantly younger than their DYS counterparts. Consistently, respondents with DD showed more comorbidity and impairment than those with MD or DYS. Even when the effects of other correlates were controlled, the individuals with DD had a greater likelihood of having a concurrent anxiety disorder and more impairment in their functioning compared with individuals with MD. This likelihood is more than twofold compared to the difference between individuals with DD and those with DYS (data not shown). These findings suggest that somatization, physical illness, lack of self-reliance and the use of mental health services among people with DD are associated with the presence of anxiety, functional impairment, or both. In addition, individuals with DD were twice as likely to recognize a mental health problem as people with DYS (data not shown).

\section{Implications of Findings}

Results from this study may have implications for theory, practice and research. Assuming that the current diagnostic classification system, the DSM, identifies with sizeable accuracy people suffering from DYS, MD and $\mathrm{DD}$, the lack of sharp and consistent distinctions between the diagnostic groups in this study does not contribute to supporting the pure categorical perspective. Our observations add to the emergent consensus in the psychiatric literature that the current categorical classification of the depressive disorders should be reassessed and that a more useful format for both research and clinical practice should be developed $[2,10,38,39]$. As proposed by other authors, a dimensional system that incorporates these categories could be useful [40-42]. The recognition of diverse forms of depression as discrete entities that form 
part of a single dimension will impact the criteria used to define patient groups as well as the measurement of recovery rates, relapse and associated factors.

If depressive disorders really do manifest in a spectrum, patients would need more aggressive treatment from an early stage of the illness in order to avoid deterioration and co-occurrence with other psychological disorders, as we observed with the comorbidity and impairment in the DD group. As stated by McCollough [43], the psychopathology of chronic depression is related to changes in the cognitive-emotional structure of patients due, in part, to the lack of remission of depressive symptoms of an acute episode. Thus, timely interventions could reduce the probability of fulfilling diagnostic criteria for chronic depression and its associated costs and morbidity [44-45]. In addition, because the study participants with DYS were significantly less likely to use formal mental health services and those with MD were significantly more likely to rely on themselves to solve their emotional problems, early interventions should transcend the clinical practice setting and reach the general population through community, school and employment-based activities and through mass media [46]. Moreover, the finding that people with DD were the most likely to report comorbid anxiety, somatization, physical illness, functional impairment and lack of self-reliance should alert clinicians to the need to formulate more complete evaluations and to develop a comprehensive treatment plan for these patients. This finding also suggests that these individuals have a more serious form of depressive psychopathology that needs to be carefully studied in order to provide appropriate treatment [43, 47].

Nativity has been differentially associated with the morbidity of several psychiatric disorders in various Hispanic groups [48], but there is still a need for studies specifically related to psychiatric nosology that are carried out in a variety of populations using the same measures. The results from our investigation should be integrated into the current state of knowledge, and they may promote similar research with other Latino populations, a rapidly growing group in the United States in recent decades.

\section{Limitations and Strengths}

The findings from this study should be interpreted in light of various limitations. First, because the present study undertook secondary data analysis, the explored relationships were limited to the information gathered in the original study and other differences between the groups could not be evaluated. For instance, the definition of depressive diagnoses and some of the clinical mea-

Correlates of Unipolar Depressive Disorders sures are based on the preceding year and do not provide specific information about the acuity or severity of illness at the time of data collection. It is possible that studying only people with current or active disorders might have revealed somewhat different relationships. In addition, we were not able to compare the three groups on some variables that have distinguished them in previous studies. Also, some of the variables in the study were not measured using standardized instruments (social support, physical illness). Second, data from this study came from a cross-sectional design; thus, causal relationships cannot be established since factors associated with the disorder can be either antecedents or consequences. Third, inpatients and subthreshold disorders were not considered in this sample, hindering the application of results to severely disturbed patients and disorders at the symptom level. Finally, generalization of the findings to other cultural groups and socioeconomic characteristics must await verification.

Despite its constraints, this study has considerable strengths and extends previous research in various aspects. First, to the best of our knowledge, this is the first study with adult Latinos that compares individuals with DYS, MD and DD in an array of demographic, clinical and psychosocial variables and that attempts to identify which predictors are better associated with each of these disorders. This research contributes to the external validity of other studies with similar findings by addressing the issue with an ethnically homogeneous Latino population. Second, many of the studies carried out so far with individuals who fulfill the criteria for DYS and MD have used clinical samples and diagnostic measures that are self-administered. Thus, it is a strength that our study was populationbased, used face-to-face structured interviews and included a larger sample of dysthymic persons than has been reported by other researchers [17]. Importantly, these findings contribute to generate hypotheses that can be further explored using longitudinal designs. Specifically, future research should attempt to extend current findings by exploring other areas proposed in Cantwell's model [10] such as biological and genetic factors, natural history of the condition and response to treatment. Although a challenge, it would also be useful to carry out studies with incident cases in order to minimize the margin of error introduced by the length of time the person has been experiencing episodes of the illness. This will facilitate the identification of specific risk factors for the unipolar depressive conditions. Finally, using standard measures for all the variables under study will increase the reliability of results and improve comparison across studies.

Psychopathology 2013;46:163-171 


\section{Conclusions}

On the basis of our comparison and associations of demographic, clinical and psychosocial correlates among adults who fulfilled the diagnostic criteria for MD, DYS and DD, we conclude that these depressive conditions are not completely different from each other, but instead they vary in some aspects and are alike in others. As stated by other authors [40], the spectrum concept does not ignore the DSM approach but instead incorporates and expands it. Hence, considering unipolar depression as a broad spectrum in which specific clusters can be identified may be a more appropriate approach to understanding depressive conditions. Our findings add to the proposal that the mood disorder section of the DSM be modified and expanded to: (1) include a depressive spectrum of unipolar depression and (2) incorporate in it DD, a form of chronic depression for which there is no current standard. In addition, the fact that the main observed differences were between MD and DD, while DYS seemed to share common characteristics with each of them, suggests the possibility that DYS can be placed between these two other depressive disorders in the hierarchical classification of depression established by Angst et al. [17]. Replication of this investigation with different populations and analysis of longitudinal correlates of individuals with DYS will contribute to the verification of this proposition. Also, extending the present findings by investigating oth- er areas proposed in Cantwell's model (biological and genetic factors, natural history of the condition, and response to treatment) [10], as well as other clinical and etiologically relevant variables that have distinguished MD from DYS and DD in previous studies, is warranted. Much more comparative work needs to be done before clear-cut conclusions can be drawn regarding the continuity controversy of unipolar depressive disorders. Nevertheless, efforts to inform and contribute to this controversy have implications for research and the DSM-V underpinnings and will help practitioners to design and deliver better interventions for both prevention and treatment.

\section{Acknowledgements}

This research was supported by grant R01-MH42655 from the National Institute of Mental Health. The manuscript was supported in part by a CURE Diversity Supplement to the R25T CA57730. The authors thank Dr. Marisol Peña Orellana for her invaluable support in the initial preparation of the databases required to conduct the analyses, and Dr. Rafael Ramirez for his thoughtful comments in the revision of the manuscript.

\section{Disclosure Statement}

The authors report no conflicts of interest related to this work.

\section{References}

1 Jablensky A: Boundaries of mental disorders. Curr Opin Psychiatry 2005;18:653-658.

$\checkmark 2$ Widiger TA, Samuel DB: Diagnostic categories or dimensions? A question for the Diagnostic and Statistical Manual of Mental Disorders - fifth edition. J Abnorm Psychol 2005; 114:494-504.

3 Vallejo J, Baca E, Cervera S, Cuenca E, Leal C, Roca M: Problemas conceptuales y de clasificación; in Cervera S, Baca E, Leal C, Vallejo J, Cuenca E (eds): Trastornos del Humor. Madrid, Editorial Medica Panamericana, 2000, pp 45-58.

4 Hankin BL, Fraley RC, Lahey BB, Waldman ID: Is depression best viewed as a continuum or discrete category? A taxometric analysis of childhood and adolescent depression in a population-based sample. J Abnorm Psychol 2005; 114:96-110.

5 Lavretsky H, Kumar A: Clinically significant non-major depression: old concepts, new insights. Am J Geriatr Psychiatry 2002;10:239255 .
6 Ruscio J, Ruscio AM: Informing the continuity controversy: a taxometric analysis of depression. J Abnorm Psychol 2000;109:473487.

7 Solomon A, Haaga DA, Arnow BA: Is clinical depression distinct from subthreshold depressive symptoms? A review of the continuity issue in depression research. J Nerv Ment Dis 2001;189:498-506.

-8 Santor DA, Coyne JC: Evaluating the continuity of symptomatology between depressed and nondepressed individuals. J Abnorm Psychol 2001;110:216-225.

\$9 Rihmer Z, Szadoczky E: Dexamethasone suppression test and TRH-TSH test in subaffective dysthymia and character-spectrum disorder. J Affect Disord 1993;28:287-291.

10 Cantwell DP: Classification of child and adolescent psychopathology. J Child Psychol Psychiatry 1996;37:3-12.
11 Robins E, Guze SB: Establishment of diagnostic validity in psychiatric illness: its application to schizophrenia. Am J Psychiatry 1970;126:983-987.

12 Goldney RD, Fisher LJ: Double depression in an Australian population. Soc Psychiatry Psychiatr Epidemiol 2004;39:921-926.

13 Rihmer Z, Angst J: Mood disorders: epidemiology; in Sadock BI, Sadock VA (eds): Kaplan \& Sadock's Comprehensive Textbook of Psychiatry, ed 8. Philadelphia, Lippincott Williams \& Wilkins, 2005, pp 15751582.

14 Akiskal HS: Dysthymic disorders: psychopathology of proposed chronic depressive subtypes. Am J Psychiatry 1983;140:11-20.

15 Rihmer Z: Dysthymic disorder: implications for diagnosis and treatment. Curr Opin Psychiatry 1999;12:69-75.

16 Judd LL: Pleomorphic expressions of unipolar depressive disease: summary of the 1996 CINP President's Workshop. J Affect Disord 1997;45:109-116. 
17 Angst J, Sellaro R, Merikangas KR: Depressive spectrum diagnoses. Compr Psychiatry 2000;41(suppl 1):39-47.

18 Keller MB, Lavori PW: Double depression, major depression, and dysthymia: distinct entities or different phases of a single disorder? Psychopharmacol Bull 1984;20:399402.

19 Goodman SH, Schwab-Stone M, Lahey BB, et al: Major depression and dysthymia in children and adolescents: discriminant validity and differential consequences in a community sample. J Am Acad Child Adolesc Psychiatry 2000;39:761-770.

20 McCullough JP Jr, Klein DN, Borian FE, et al: Group comparisons of DSM-IV subtypes of chronic depression: validity of the distinctions. Part 2. J Abnorm Psychol 2003;112: 614-622.

21 Keller MB, Shapiro RW: 'Double depression': superimposition of acute depressive episodes on chronic depressive disorders. Am J Psychiatry 1982;139:438-442.

22 American Psychiatric Association: Diagnostic and Statistical Manual of Mental Disorders, DSM-IV-TR, ed 4, rev. Washington, American Psychiatric Association, 2002.

23 Kupfer DJ, First MB, Regier DA (eds): A Research Agenda for DSM-V. Washington, American Psychiatric Association, 2002.

-24 McCullough JP Jr, Klein DN, Keller MB, et al: Comparison of DSM-III-R chronic major depression and major depression superimposed on dysthymia (double depression): validity of the distinction. J Abnorm Psychol 2000;109:419-427.

-25 Remick RA, Sadovnick AD, Lam RW, Zis AP, Yee IM: Major depression, minor depression, and double depression: are they distinct clinical entities? Am J Med Genet 1996;67:347353.

26 Szadoczky E, Fazekas I, Rihmer Z, Arato M: The role of psychosocial and biological variables in separating chronic and non-chronic major depression and early-late-onset dysthymia. J Affect Disord 1994;32:1-11.
27 Angst J, Merikangas K: The depressive spectrum: diagnostic classification and course. J Affect Disord 1997;45:31-40.

28 Gonzalez-Tejera G, Canino G, Ramirez R, et al: Examining minor and major depression in adolescents. J Child Psychol Psychiatry 2005;46:888-899.

29 Albizu-García CE, Alegría M, Freeman D, Vera M: Gender and health services use for a mental health problem. Soc Sci Med 2001;53: 865-878.

30 Alegría M, McGuire T, Vera M, et al: The impact of managed care on the use of outpatient mental health and substance abuse services in Puerto Rico. Inquiry 2001;38:381-395.

31 Vera M, Alegría M, Freeman DH, et al: Help seeking for mental health care among poor Puerto Ricans: problem recognition, service use and type of provider. Med Care 1998;36: 1047-1056.

32 Bravo M, Canino GJ, Rubio-Stipec M, Woodbury-Farina M: A cross-cultural adaptation of a psychiatric epidemiologic instrument: the diagnostic interview schedule's adaptation in Puerto Rico. Cult Med Psychiatry 1991;15:1-18.

33 Rubio-Stipec M, Bravo M, Canino G: La entrevista diagnóstica internacional compuesta (CIDI): un instrumento epidemiológico adecuado para ser administrado conjuntamente con otros sistemas diagnósticos en diferentes culturas. Acta Psiquiatr Psicol Am Lat 1991;37:191-204.

34 Flament MF, Cohen D, Choquet M, et al: Phenomenology, psychosocial correlates, and treatment seeking in major depression and dysthymia of adolescence. J Am Acad Child Adolesc Psychiatry 2001;40:1070 1078.

35 Ortega AN, Alegría M: Self-reliance, mental health need and the use of mental health care among island Puerto Ricans. Ment Health Serv Res 2002;4:131-140.

36 Kleinbaum DG, Klein M: Logistic Regression: A Self-Learning Text, ed 2. New York, Springer, 2002, pp 267-299.

- 37 Lara ME, Klein DN, Kasch KL: Psychosocial predictors of the short-term course and outcome of major depression: a longitudinal study of a nonclinical sample with recentonset episodes. J Abnorm Psychol 2000;109: 644-650.
38 Cuthbert BN: Dimensional models of psychopathology: research agenda and clinical utility. J Abnorm Psychol 2005;114:565-569.

39 Regier DA: Dimensional approaches to psychiatric classification: refining the research agenda for DSM-V: an introduction. Int J Methods Psychiatr Res 2007;160:S1-S5.

40 Maser JD, Patterson T: Spectrum and nosology: implications for DSM-V. Psychiatr Clin North Am 2002;25:855-885.

41 Kendell R, Jablensky A: Distinguishing between the validity and utility of psychiatric diagnoses. Am J Psychiatry 2003;160:4-11.

42 Widiger TA, Clark LA: Toward DSM-V and the classification of psychopathology. Psychol Bull 2000;126:946-963.

43 McCullough JP Jr: Treatment for Chronic Depression: Cognitive Behavioral Analysis System of Psychotherapy. New York, Guilford Press, 2003.

44 Nobile M, Cataldo GM, Marino C, Molteni M: Diagnosis and treatment of dysthymia in children and adolescents. CNS Drugs 2003; 17:927-946.

45 Russell JM, Hawkins K, Ozminkowski RJ, et al: The cost consequences of treatment-resistant depression. J Clin Psychiatry 2004;65: 341-347.

46 Corrigan P, Gelb B: Three programs that use mass approaches to challenge the stigma of mental illness. Psychiatr Serv 2006;57:393399.

47 Klein DN, Santiago NJ, Vivian D, et al: Cognitive-behavioral analysis system of psychotherapy as a maintenance treatment for chronic depression. J Consult Clin Psychol 2004;72:681-688.

-48 Alegría M, Canino G, Stinson F, Grant BF: Nativity and DSM-IV psychiatric disorders among Puerto Ricans, Cuban Americans, and Non-Latino Whites in the United States: results from the National Epidemiologic Survey on alcohol and related conditions. J Clin Psychiatry 2006;67:56-65. 